\title{
Parental Language Input to Children at Stuttering Onset
}

\section{Stephanie Miles Nan Bernstein Ratner University of Maryland College Park}

\begin{abstract}
Many programs for the indirect management of stuttering in early childhood counsel adjustment of parental language models, which are presumed to play an exacerbating influence on vulnerable children's fluency. We examined the relative levels of linguistic demand in maternal language to stuttering and nonstuttering children, adjusted for each child's current level of linguistic development. N o significant or observable differences were detected in the relative level of linguistic demand posed by parents of stuttering children very close to onset of symptoms. Empirical support for current advisement and potential ramifications are discussed.
\end{abstract}

\section{KEY W ORDS: child, stutter, language, parent}

$\mathrm{T}$ he widespread assumption that parental verbal behavior may be related to the initiation, development, and quality of stuttering behavior in children has motivated empirical investigations and guided direct and indirect therapeutic interventions for several decades (Conture \& Melnick, 1999; Guitar, 1998; Shapiro, 1999; Wall \& Myers, 1995). Van Riper, whose advice on the onset, nature, and treatment of stuttering became axiomatic among professionals, suggested that dysfluency often ensues "when the speech models provided by the parents or siblings of the child are too difficult for him to follow" (1973, p. 381). More recently, Starkweather and colleagues (Starkweather \& Gottwald, 1990; Starkweather, Gottwald, \& Halfond,1990) proposed a theoretical framework for understanding the development of stuttering in children. This framework, known as the Demands and Capacities Model (DCM), is based on the notion that stuttering develops when the demands for fluency placed on children by themselves and/or their listeners exceed the children's cognitive, linguistic, motoric, or emotional capacities to respond fluently. Specifically, Starkweather et al. have suggested that syntactically and semantically complex parental language models impose a level of demand that might challenge children's capacities for fluency. Despite the popularity of this notion and its influence on recommendations given to parents of children who stutter (e.g., Rustin \& Cook, 1995), efforts to demonstrate a correlation between parental speech characteristics and children's fluency have yielded results that are ambiguous and difficult to interpret (Bernstein Ratner, 1993; Guitar et al., 1992; Nippold \& Rudzinski, 1995; Yairi, 1997). 


\section{Parental Speech Style and Children's Fluency}

The bulk of the literature on parent-child interaction and stuttering has sought to determine whether specific parental verbal behaviors such as rate, turntaking, lexical and syntactic characteristics, and other aspects of parental conversational style enhance or aggravate children's fluency. Few of these behaviors have motivated as much investigation as that of parental speech rate. Although numerous comparison and intervention studies have examined this aspect of parental verbal interaction, they have neither demonstrated unequivocally that rapid parental speech rates exacerbate stuttering in children nor generated conclusive evidence of rate differences among mothers of children who stutter and mothers of normally fluent children (Kelly \& Conture, 1992; Kloth et al., 1995; Meyers \& Freeman, 1985a, 1995b, 1995c; Schulze \& Johannsen, 1991; Stephenson-Opsal \& Bernstein Ratner, 1988; Yaruss \& Conture, 1995). Other factors thought to heighten communicative time pressure and demand, including interruptions, "simultalk" (the degree to which turns in a conversation overlap, such that speakers are talking simultaneously), decreased interspeaker latency, and question-asking, have proven equally challenging to link to fluency failure in children (Bernstein Ratner, 1992; Kelly \& Conture, 1992; Langlois, Hanrahan, \& Inouye, 1986; Newman \& Smit, 1989; Weiss \& Zebrowski, 1991; Wilkenfeld \& Curlee, 1997).

\section{Parental Linguistic Behaviors and Children's Fluency}

Various attributes of parental linguistic behavior also have been the subject of research on parent-child interactions and stuttering, although significantly more attention has been given to examining linguistic differences among stuttering and normally fluent children. Given that clinicians frequently advise parents of children who stutter or who are suspected of having a stuttering problem to simplify their speech, it seems important to determine (a) whether parents of children who stutter and fluent children actually differ in the semantic/syntactic complexity of their linguistic input, and (b) whether this aspect of linguistic input has any observable or definable impact on children's fluency.

Prior investigations of potential linguistic differences in parents of stuttering and normally fluent children primarily have compared either the distributions of various linguistic forms in their speech (e.g., relative use of interrogatives, negatives, imperatives) (KasprisinBurrelli, Egolf, \& Shames, 1972; Langlois, Hanrahan, \& Inouye, 1986). Others have addressed the length and/or linguistic complexity of their utterances (Kloth et al.,
1995; Yaruss \& Conture, 1995). Langlois, Hanrahan, and Inouye (1986) noted that mothers of children who stutter used more imperative and interrogative utterances than the comparison-group mothers, who used more statements. This finding was used as support for the notion of linguistic differences between parents of stuttering and normally fluent children and, ultimately, as support for offering specific advice regarding linguistic and stylistic adjustments to parents of children who stutter. However, as with much of the literature on parentchild interactions and stuttering, these results were based on data from a small sample of children who stutter and their mothers, with a wide range of ages represented among the children. Both of these factors impede the generalization of these outcomes much beyond the participants themselves. Furthermore, studies such as this one, in which the amount of time elapsed since the onset of stuttering symptoms varies widely among participants, do not contribute much to our deconstruction of the "chicken/egg phenomenon," as it relates to parent-child interactions and stuttering. That is, if we hypothesize that parents' communicative interactions with their children might change because of the stuttering, it seems clear that such adjustments would evolve over time and vary in nature and degree as the stuttering behavior was further instantiated. Conversely, if a pattern of verbal behaviors that differentiated parents of children who would later be diagnosed as having a stuttering problem from parents of fluent children were observed before the onset of stuttering, these behaviors would most likely not be responses to any overt speechrelated differences in the children. Rather, they might be proposed as causal factors in the onset of stuttering. It is much more challenging to tease out who is influencing whom after the onset of stuttering. Characteristics of parental input are just as likely to change in response to the child's dysfluencies as they are to affect the child's fluency (Bernstein Ratner, 1993; Kelly, 1993).

To better evaluate the presence of linguistic differences among mothers of children who would go on to stutter and mothers of fluent children, Kloth et al. (1995) developed a prospective study in which they examined communicative behaviors of mothers of preschool children at elevated genetic risk for stuttering. Children were considered at risk for developing a stuttering problem if at least one of their parents was a diagnosed stutterer. Speech samples of all mothers were collected before any child had been diagnosed as having a stuttering problem. One year later, samples were compared between mothers whose children were diagnosed as stutterers and those whose children remained normally fluent. The authors observed that mothers of children who were diagnosed as having a stuttering problem one year after the study did not differ significantly from mothers of children who remained fluent on measures of speech 
rate or communicative style (e.g., non-intervening, explaining, directing). However, mothers of the future stutterers were found to use significantly less complex language (i.e., shorter mean lengths of utterance) than mothers of fluent children. This outcome is counter to popular claims that children whose parents use more complex language are more susceptible to developing a stuttering problem; therefore the claim warrants additional investigation.

Furthermore, although the prospective design used by Kloth et al. would be challenging to replicate, the study underscores the need to take parent-child speech samples as close to the onset of stuttering symptoms as possible. Doing so will help us to separate the influence of preexisting (i.e., preceding onset) parent variables on children's verbal behavior from parental behaviors that develop after the onset of, and in reaction to, children's stuttering.

In addition to the methodological problems inherent in studying groups of children with widely varying elapsed time post onset of stuttering, the heterogeneity of the stuttering population and the multidimensionality of the disorder further limit generalization of findings regarding various aspects of parent-child interactions beyond individuals or subgroups (Kelly, 1993). These issues appear to have prompted a shift in focus from making between-group comparisons of parent behaviors to analyzing these variables on a more individual basis. Yaruss and Conture (1995) attempted to more clearly pinpoint the effects of parental speaking rates and utterance lengths on children's fluency by measuring differences in these variables both across groups (mothers of children who stutter and mothers of normally fluent children) and in adjacent parent-child utterances within dyads. A significant positive correlation was found between the children's Total Overall Scores on the Stuttering Severity Instrument (SSI) and dyadic speaking rate differences (i.e., difference between the speech rates of a parent and child). In other words, the greater the difference between specific parent and child speech rates, the more severely the child stuttered. As significant differences were not evident in speaking rates of mothers of children with mild versus moderate dysfluencies or in the rates of these children themselves, it appeared that the degree of the dyadic difference in rate was the characteristic that best distinguished these groups. The authors' evaluation of dyadic differences, in addition to group comparisons, reflects an acknowledgment of the heterogeneity of this population and should continue to guide research on stuttering.

Research outcomes, to date, on parent-child interactions and stuttering present a scattered picture, with no definitive evidence of inherent differences between parents of children who stutter and parents of fluent children. What remains clear is the need for additional studies that examine individual cases and subgroups because of the inadequacy of group summaries in delineating relationships among parent-child behaviors (Nippold, 1990; Schwartz \& Conture, 1988; Watkins \& Yairi, 1997). Additionally, selection of participants close to the time of onset of stuttering is critical if we are to examine differences in parent behaviors before they have been (overly) shaped by the children's dysfluencies.

With respect to specific aspects of parent-child interactions, the literature seems to be disproportionately attentive to a small set of variables implicated as sources of communicative time pressure (e.g., parental speech rate, interspeaker latency). Investigations pertaining to the influence of parental linguistic input-syntactic and semantic - on children's fluency are relatively sparse, although clinicians continue to advise parents of children who stutter to simplify their linguistic input as a means of promoting fluency. There is a large extant literature supporting relationships between parental language characteristics and children's development of language, making the study of linguistic input to children who stutter quite relevant to clinical advisement, because such advisement may not only be not efficacious, but potentially harmful to the child's communicative development. Specifically, evidence from language acquisition literature strongly links patterns of adult input to outcome performance on various language measures by children (Bruner, 1983; Gleitman, Newport, \& Gleitman, 1984; Murray, Johnson, \& Peters, 1990).

\section{Analysis of Parental Speech to Children Developing Language}

There is no shortage of evidence that parents adapt various features of their language to the developmental level of their children. Studies that have examined language characteristics of parental speech to children have used a number of different measures to analyze parents' language characteristics. These analyses have been undertaken across all linguistic domains, including phonology, morphology, lexicon, semantics, syntax, pragmatics, and paralinguistics. In this section, some such measures are reviewed, and their relative value assessed. Specifically, analyses of syntactic and lexical characteristics of parents' speech to children will be reviewed here, as these areas are the focus of the present study.

\section{Syntax}

Mothers generally reduce the length and complexity of their utterances when speaking to their young children (Rondal, 1985; Snow, 1972). Mean Length of Utterance (MLU; Brown, 1973) is one of the most regularly cited measures of syntactic proficiency in the 
literature on language development. Although it is considered only a "gross index of language development" (Bloom \& Lahey, 1978), MLU has been strongly and reliably correlated with age both in normally developing children and in children with cognitive and linguistic impairments (Brown, 1973; Klee, 1992; Miller \& Chapman, 1981; Snow, 1986). Although this measure's sensitivity to grammatical development appears to plateau beyond MLU 4.0 (morphemes), it is commonly used in studies on parental speech to children, especially in comparing the syntactic complexity of parents' language to that of their children (Rondal, 1985).

Although it appears less frequently in language acquisition literature than does MLU, Mean Pre-Verb Length (MPVL) has also been used to estimate the syntactic complexity of parents' and children's speech (Bernstein Ratner, 1992; Cross, 1977; Fey, Leonard, \& Wilcox, 1981; Sachs \& Devin, 1976; Snow, 1972). MPVL, calculated as the number of morphemes before the main verb in each clause, has been positively correlated with age in children (Cross, 1977). Further, Snow (1972) demonstrated significant differences in MPVL for mothers' speech to 2-year-old versus 10-year-old children and suggested that it might be a more sensitive measure of syntactic complexity than MLU, as it scores for leftbranching and center-embedding. Other measures used in studies on language acquisition to analyze syntactic complexity have provided a more global representation of syntactic proficiency.

One such measure was developed by Blake, Quartaro, and Onerati (1993) and codes language samples for the presence of adult grammatical elements on four levels: clause, phrase, word, and phrasal expansion. This measure has been employed in a growing number of recent studies examining mother-child interaction, both within and outside the field of stuttering (e.g., Bonelli, Dixon, Bernstein Ratner, \& Onslow, 2000; Melnick \& Conture, 2000; Botting, Conti-Ramsden, \& Crutchley, 1997). Instructions for coding this measure (referred to as SYNCOM in this paper) are provided in the Appendix. Unlike MLU and MPVL, SYNCOM is sensitive to syntactic variations that might differentiate adults' speech and, therefore, might illustrate parents' syntactic adaptations when speaking to young children more accurately than MLU and MPVL.

\section{Lexicon}

Various aspects of lexical use have been examined in language acquisition literature. As is true for syntax, it is clear that mothers of children learning language adapt their lexical complexity to match closely the levels of complexity of their children's speech. Two fairly common indices of lexical complexity are (a) lexical diversity and (b) relative frequency of lexical terms.
Number of Different Words (NDW) is widely used as an estimate of children's lexical proficiency. It is calculated by totaling the number of different word types represented in a speech sample. Its adequacy as a measure of semantic diversity, or "lexical density" (Klee, 1992), has been suggested by a number of researchers (Klee, 1992; Templin, 1957; Watkins et al., 1995), who have demonstrated its positive correlation with age in both conversational and narrative samples. Its counterpart, Type-Token Ratio (computed by dividing the number of different words by the total number of words in a sample), has also been shown to vary in adults' speech to children of different ages, with lower values evident in parents' speech to younger children and higher values evident in their speech to older children. Diversity of lexical input has been strongly associated with children's vocabulary profiles and lexical growth (e.g., Bornstein, Haynes, \& Painter, 1998).

Lexical rarity, or the relative complexity of vocabulary used by a speaker, has largely been used to characterize parents' speech to children learning language. Parents, and especially mothers, typically use vocabulary consisting of the most frequently occurring words in the language when speaking to young children (Rondal, 1985; Snow, 1972). Conversely, use of infrequent or rare words of the language has been thought to represent a form of conversational demand on children (Bernstein Ratner, 1988) and has been shown to affect the growth of children's expressive lexicons (Beals, 1997; Beals \& Tabors, 1995). Lexical rarity is typically calculated by comparing the words used in a speech sample to a designated set of common words from a frequency list.

\section{Conversational Participation}

Yet one other related measure that has been investigated to evaluate parental language interactions with young children-albeit more broadly than measures of syntactic and lexical characteristics-is Mean Length of Turn (MLT). MLT is considered a "rough measure of conversational participation" (Sokolov \& Snow, 1994, p. 34) and is thought to increase as children's conversational proficiency develops. MLT can be expressed as the mean number of words or utterances per turn.

This brief survey of approaches for analyzing parents' speech to young children illustrates the many aspects of parents' speech that are attuned to children's developmental levels. Although parents do closely match their language input to their children's linguistic proficiency, we know that this match is not exact. Researchers in language acquisition have suggested that slightly greater relative complexity of parents' speech is a critical factor in the children's development of language (Cross, 1977; Huttenlocher, 1998; Murray, Johnson, \& Peters, 1990; Rondal, 1985). 
Given prevailing assumptions regarding the interdependency of parental language characteristics and children's acquisition of language, the present study was undertaken to test claims that children who stutter experience linguistic demands imposed by sophisticated parental models. Specifically, we examined language differences among parents of children who stutter and parents of fluent children; differences between parentchild dyads within these groups were also examined. As research on parental linguistic input to children who stutter, to date, has focused primarily on the analysis of syntax and communicative intent, this study diverged and included measures of lexical diversity and rarity (word frequency) in the analyses, in addition to several broad measures of syntactic complexity. A measure of general communicative proficiency was included as well. These analyses were guided by two questions: (a) Do parents of children who stutter differ from parents of normally fluent children on measures of lexical diversity, rarity, and syntax? and (b) Do dyads of parents/ children who stutter and parents/nonstuttering children differ in the discrepancies between partners on these measures?

\section{Method \\ Participants}

Participants were 12 children (10 boys and 2 girls) who were diagnosed as having a stuttering problem; 12 age- (within 3 months CA), gender-, and SES-matched normally fluent comparison children; and the mothers of the children in these two groups. These children, who were recruited for a larger study, ranged in age from 27 to 48 months at the initial evaluation, with a mean age of 36.7 months ( $S D=6.4)$ for children who stutter (CWS) and 35.5 months $(S D=4.9)$ for the children who did not stutter (CWDNS). The children came from middle- to upper-class families, with a mean level of maternal education of 16 years in each group. All children and their mothers were native monolingual speakers and used a standard dialect of American English. Interviews with the parents of CWS revealed that all children were within 3 months of stuttering onset at the time speech samples were collected. The mean elapsed time since onset of stuttering symptoms was $2.75(S D=0.97)$ months. None of the children had a history of speech and language problems, apart from stuttering symptoms, nor had they been seen for a speech and language evaluation before the date of testing for this study.

\section{Background Information for the Children}

Data pertaining to each participant's speech, language, and motor development and medical and social history were obtained through case history questionnaires that were completed by the children's mothers.

Analysis of spontaneous language samples gathered from mothers and CWS (procedure described below) revealed a mean stuttering frequency of $9.11 \%$ stuttered words for the children (range: $3 \%-25.5 \%$ stuttered words). For this calculation, the following phenomena were coded as stuttering behaviors: sound, syllable, and monosyllabic whole-word repetition, blocks, and prolongations. No fluent child demonstrated more than $2 \%$ stutter-like dysfluencies during evaluation.

All children participated in an extensive speechlanguage assessment protocol, the results of which have been summarized in Bernstein Ratner and Silverman (2000). All participants demonstrated receptive and expressive language skills within normal limits, as evidenced by their performance on a battery of standardized tests, including the Expressive One Word Picture Vocabulary Test-Revised (Gardner, 1990), the Peabody Picture Vocabulary Test-Revised (Dunn \& Dunn, 1981), and two subtests of the Clinical Evaluation of Language Fundamentals-Preschool (Wiig, Secord, \& Semel, 1992) (Word Structure and Linguistic Concepts). All children save one also demonstrated age-appropriate articulation skills, as determined by performance on the Goldman-Fristoe Test of Articulation (Goldman, R., \& Fristoe, M., 1986). As reported in Bernstein Ratner \& Silverman (2000), although the children in both groups performed solidly within the average range, the mean scores of CWS fell below those of CWDNS on every standardized measure, with these comparisons reaching significance for two measures (EOWPVT-R and CELF-P, Linguistic Concepts). No child demonstrated oral motor or hearing dysfunction by report or observation. Results of standardized tests are summarized in Table 1.

The mothers in the study completed two checklists pertaining to their children's linguistic and

Table 1. Children's mean percentile scores on standardized tests of language and articulation.

\begin{tabular}{llll}
\hline \multicolumn{1}{c}{ Measure } & $\begin{array}{c}\text { M } \\
\text { (CW S) }\end{array}$ & $\begin{array}{c}\text { M } \\
\text { (CW DN S) }\end{array}$ & $\begin{array}{c}\text { Mann-Whitney } \\
\text { Wilcoxon Z }\end{array}$ \\
\hline EO W PVT-R (percentile) & 69.6 & 84 & $-1.7054^{*}$ \\
CELF-P: Linguistic Concepts & 48.31 & 75.3 & $-2.2498^{* *}$ \\
CELF-P: W ord Structure & 49.8 & 67.3 & \\
PPVT-R & 62.7 & 71.1 & \\
GFTA & 54.2 & 67.1 & \\
\hline
\end{tabular}

Notes. EO W PVT-R = Expressive 0 ne-W ord Picture Vocabulary TestRevised, CELF-P = Clinical Evaluation of Language FundamentalsPreschool, PPVT-R = Peabody Picture Vocabulary Test-Revised, $\mathrm{GFTA}=\mathrm{G}$ oldman-Fristoe Test of A rticulation

$* p<0.05$

$* * p<0.02$ 
communicative abilities: The MacArthur Communicative Development Inventory-Toddler (MCDI; Fenson, Dale, Reznick, Thal, Bates, Hartung, Pethick, \& Reilly, 1993) and the Speech and Language Assessment Scale (SLAS; Hadley \& Rice, 1993). The parental measures were used to appraise perception of the children's development for comparison with standardized measures, rather than as language assessment measures per se. Maternal ratings of their children's linguistic abilities concurred with the normal-limits scores received by all children on the standardized tests discussed above; all children were rated as exhibiting average to aboveaverage language skills (Bernstein Ratner \& Silverman, 2000). Thus, based on both standardized test performance and parental ratings, all children appeared to be developing language normally.

\section{Procedure}

Data collection took place in a sound-treated observation suite. Mother-child spontaneous language samples were gathered using a standard set of toys (medical kit, plastic food, blocks). Interactions between the mothers and their children were recorded using a video camera and an audiotape recorder. Two observers performed on-line tallies of the number of utterances produced by the child that qualified for the intended language analyses to ensure that at least 50 eligible utterances were recorded. Utterances were considered eligible if they contained at least one clause. Language samples for the mothers also included a minimum of 50 eligible utterances. The parent-child conversational samples were transcribed and formatted using the conventions of CHAT (Codes for the Human Analysis of Transcripts; MacWhinney, 2000) by two graduate assistants. Conventions for "morphemicizing" speech were used to code a duplicate set of transcripts for calculation of morpheme-based measures.

\section{Measures}

For the purposes of the present study, several language analyses were performed on the transcribed conversational samples of parents and children using the following CLAN (Computerized Language Analyses; MacWhinney, 2000 ) programs: Mean Length of Utterance, Number of Different Words, and Mean Length of Turn. The remaining measures were computed by hand. All measures were computed for child and adult participants.

\section{Syntactic Complexity}

As a guiding principle, we used the largest potential sample size appropriate to the measure employed. Because different complexity measures require and/or exclude different types of structures, the minimum sample size for each of the three syntactic measures differed. Mean Length of Utterance (MLU), the least restrictive measure in terms of utterance eligibility, was calculated on the first 100 utterances. Fillers (e.g., $u h$, $o h, \mathrm{~mm}$ ) were filtered from the count. Specific procedures followed in calculating Mean Pre-Verb Length (MPVL) and Syntactic Complexity (SYNCOM; Blake, Quartaro, \& Onerati, 1993) are outlined in the Appendix. MPVL for each subject was determined by counting the number of morphemes before the main verb in the first 30 clauses and dividing the total number of morphemes by 30 . The denominator for this calculation was set at 30 because all but one transcript from the spontaneous language sample included at least 30 clauses that were structurally eligible for this analysis (see Appendix for criteria that exclude utterances from this analysis).

SYNCOM was calculated by (a) totaling syntactic units (described in the Appendix) within an utterance, (b) totaling these complexity scores or the total number of syntactic units in each utterance, and (c) dividing this number by the total number of utterances scored for the measure. As SYNCOM counted utterances that were excluded from the MPVL calculation, such as multiword affirmative imperatives (e.g., "come here"), the number of usable utterances was slightly greater for this measure. For the computation of SYNCOM, the denominator was set at 40 utterances because all but one transcript from the spontaneous language sample contained at least 40 clauses.

\section{Lexical Diversity and Rarity}

Number of Different Words (NDW) was calculated for the first 100 words of the transcripts. Fillers and proper names were excluded, as were inflected forms of nouns and verbs whose uninflected forms were represented in the sample (e.g., play, playing, plays).

The conversational samples were analyzed for lexical rarity using a technique outlined by Beals and Tabors (1995; see Appendix). This procedure yields a count of words that are considered rare in the lexicon, although it was impossible to determine whether some of these words were used with greater frequency (rendering them common to the children) in the homes of the children. The percentage of rare words over total words in the samples was calculated.

\section{Conversational Participation}

Mean Length of Turn (MLT) was expressed as the mean number of utterances per turn. In addition to comparing MLT across groups of mothers (and children), an MLT ratio was calculated (ratio $=$ CHI MLT, MOT MLT) to assess relative conversational participation of mothers and children in each group. Higher ratios (i.e., 
approaching 1.0) were expected for those children who were assuming more equal shares of the conversational load.

\section{Reliability}

Interrater reliability was calculated for the morphemicization of parents' and children's speech from the parent-child conversational samples. Two graduate assistants coded morphological tiers of a random subset of $20 \%$ of the transcripts. Reliability coefficients for morphemicization ranged from 0.88 to 0.95 . Intra- and interrater reliability were computed both for Mean PreVerb Length and for the Syntactic Complexity measure. The remaining procedures were computed by CLAN and therefore were completed by the first author only. For interrater reliability, two undergraduate students were trained to compute MPVL and SYNCOM (one student per measure) for a random subset of $25 \%$ of the speech samples from stuttering and nonstuttering dyads. Pearson product-moment correlations were computed between the author's and students' scores (i.e., number of morphemes before the main verb for Mean Pre-Verb Length and number of grammatical categories present for SYNCOM) for each clause. The coefficients were 0.87 for Mean Pre-Verb Length and 0.95 for Syntactic Complexity. Pearson product-moment correlations were also computed between the first author's original scores and her recalculations for $25 \%$ of the transcripts. The coefficients were 0.98 for MPVL and 0.95 for SYNCOM. Language scores submitted for statistical analysis were those computed by the first author.

\section{Data Analysis}

A nonparametric test (Mann-Whitney, corrected for tied ranks to yield a $\mathrm{Z}$ score) was used to compare the parents of children who stutter with the parents of fluent children on syntactic and semantic measures, because the assumption of equal variances was violated for some of the measures. The alpha level was set at .05 (2-tailed) for each comparison. Comparisons were computed using NCSS 2000 (Hintze, 1999). To explore the question of whether parent-child dyads including children who stutter differ from those that include fluent children in the discrepancies between partners on these measures, discrepancies between parent-child values on each measure except MLT were computed. That is, for MLU, MPVL, SYNCOM, NDW, and Lexical Rarity, each child's value was subtracted from his mother's value to obtain a "discrepancy value." The distributions of these discrepancy values were then compared across the two groups. For MLT, a ratio (child MLT, mother MLT) was computed to determine relative conversational participation.

\section{Results \\ Children's Performance}

Although comparing language performance of children who stutter and that of fluent children was not a specific focus of this study, the children's scores on the language measures will be discussed briefly, because of their relevance to later discussion of discrepancy scores. Performance of children who stutter and fluent children was statistically similar for all nonstandardized measures of linguistic ability, with the exception of lexical rarity. Mean MLU was 3.02 for children who stutter and 3.35 for fluent children (Mann-Whitney $Z=0.6640$, n.s.). Both values fall well within the expected MLU range for children at 36 months old (Miller, 1981). The mean for children who stutter (2.98) fell slightly below that of fluent children (3.28) for SYNCOM (Mann-Whitney $Z=$ 1.5017 , n.s.). Both sets of values fall within those observed in children of this age and MLU level (Blake et al., 1993). Mean MPVL was 1.55 for children who stutter and 1.49 for fluent children (Mann-Whitney $Z=$ 0.463 , n.s.). As a group, children who stutter also demonstrated slightly reduced lexical diversity (NDW mean $=41.58$ ) in comparison to that of fluent children (mean $=44.25$; Mann-Whitney $Z=0.6949$, n.s.). Both means fall slightly below those reported by Watkins et al. (1995) for samples of this length taken from slightly older children interacting with unfamiliar adults. Mean MLT was 1.40 utterances per turn for children who stutter and 1.47 for fluent children (Mann-Whitney $Z=0.3177$, n.s.). The only statistically significant difference observed in comparisons of children who stutter and fluent children was for lexical rarity. Mean lexical rarity was 0.77 (\% rare words) for children who stutter and 1.50 for fluent children (Mann-Whitney $Z=1.9669, p=0.05$ ).

\section{Parental Language Performance Hypothesis 1}

The first assumption under investigation was that parents of children who stutter would use more complex language, both syntactically and semantically, than parents of children who do not stutter. No statistically significant differences were found between the two groups of parents on any of the measures of language complexity when parental language scores were examined independently from child language scores, despite lack of Bonferroni adjustment normally made for this number of comparisons. Results are presented in detail below, and means, standard deviations, and ranges of scores for each measure are shown in Table 2.

Syntactic complexity. None of the measures of syntactic complexity differentiated mothers of children who stutter from mothers of fluent children. Mean MLU 
Table 2. Between-groups comparisons of maternal performance.

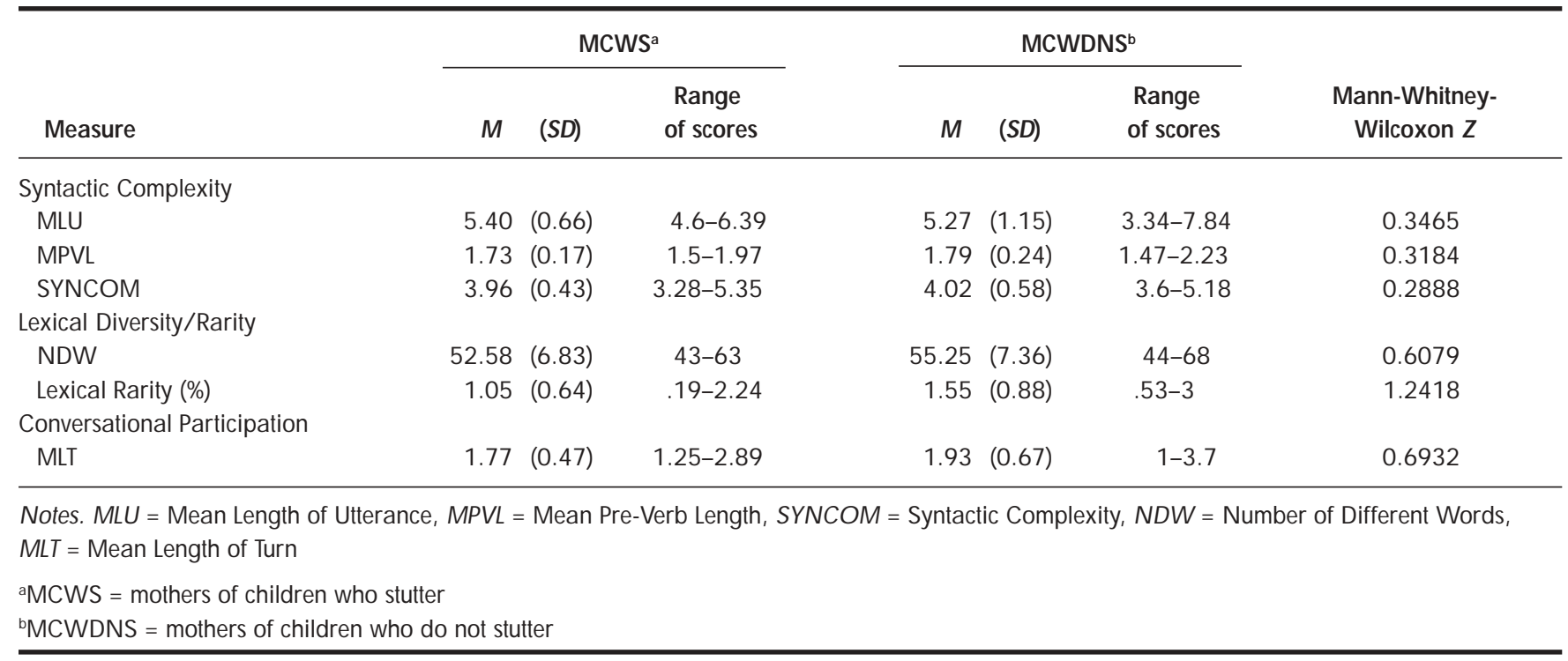

for mothers of children who stutter was 5.40, whereas the mean MLU for mothers of fluent children was 5.27 (Mann-Whitney $Z=0.3465$, n.s.). The two groups of mothers obtained very similar scores on the other measures of syntactic complexity as well. Mean MPVL was 1.73 for mothers of children who stutter and 1.79 for mothers of fluent children (Mann-Whitney $Z=0.3184$, n.s.). For SYNCOM, the mean scores were 3.96 for mothers of children who stutter and 4.02 for mothers of fluent children (Mann-Whitney $Z=0.2888$, n.s.).

Lexical diversity and rarity. As was true for analyses of syntactic complexity, the measures of lexical diversity and rarity used here failed to differentiate the two groups of parents. Mean NDW was 50.08 for mothers of children who stutter and 52.5 for mothers of children who do not stutter (Mann-Whitney $Z=0.7857$, n.s.). Findings were similar for the lexical rarity analysis. Mean percentage of rare words was $1.05 \%$ for mothers of children who stutter and $1.55 \%$ for mothers of fluent children (Mann-Whitney $Z=1.2418$, n.s.). Contrary to the anticipated outcomes, it was the mothers of fluent children who exhibited slightly greater diversity and rarity in lexical usage, although these differences were nonsignificant.

Conversational participation. Mothers in the two groups presented similarly in terms of conversational participation. Mean Length of Turn was 1.77 utterances per turn for mothers of children who stutter and 1.93 utterances per turn for comparison group mothers (Mann-Whitney $Z=0.6932$, n.s.).

\section{Hypothesis 2}

The second assumption under investigation was that the "distance" between parental scores and child scores would be larger for the group including children who stutter than for the group including fluent children. To the contrary, discrepancies in scores between mothers and children were equivalent in the two groups. Scores are summarized in Table 3 and Figure 1.

Syntactic complexity. Mean discrepancy in MLU for dyads in the stuttering group was 2.37, whereas the mean MLU discrepancy for the nonstuttering group dyads was 1.92 , a nonsignificant difference (MannWhitney $Z=0.7217$, n.s.). Likewise, mean MPVL discrepancy was 0.19 for dyads of mothers and children who stutter and 0.30 for dyads of mothers and fluent children (Mann-Whitney $Z=0.5489$, n.s.). Mean SYNCOM discrepancies were 1.04 for dyads consisting of a stuttering child and 0.68 for nonstuttering group dyads (Mann-Whitney $Z=1.2704$, n.s.).

Lexical diversity and rarity. For NDW, mean discrepancies between mother-child dyads were as follows: 8.5 for dyads including a child who stutters and 8.25 for comparison-group dyads (Mann-Whitney $Z=0.0289$, n.s.). Mean discrepancies on the measure of lexical rarity (expressed as percentages) were 0.27 for mothers and their children who stutter and 0.49 for mothers and their fluent children (Mann-Whitney $Z=0.9239$, n.s.).

Conversational participation. As with the other measures, the analysis of relative Mean Length of Turn (child-mother ratio) did not differentiate between the two groups. Mean ratios were 0.83 for dyads including a stuttering child and 0.85 for the comparison-group dyads (Mann-Whitney $Z=0.5203, p=0.60$, n.s.). 
Table 3. Means, standard deviations, and ranges of scores for dyadic discrepancies on language measures.

\begin{tabular}{|c|c|c|c|c|c|c|c|}
\hline \multirow[b]{2}{*}{ Measure } & \multicolumn{3}{|c|}{ Dyads with CW Sa } & \multicolumn{3}{|c|}{ Dyads with CW DNS ${ }^{b}$} & \multirow[b]{2}{*}{$\begin{array}{l}\text { Mann-Whitney- } \\
\text { Wilcoxon Z }\end{array}$} \\
\hline & $M$ & (SD) & $\begin{array}{l}\text { Range } \\
\text { of scores }\end{array}$ & $M$ & (SD) & $\begin{array}{l}\text { Range } \\
\text { of scores }\end{array}$ & \\
\hline \multicolumn{8}{|c|}{ Syntactic Complexity } \\
\hline MLU & 2.37 & $(0.93)$ & $0.71-3.47$ & 1.92 & $(1.15)$ & $-1.85^{c}-3.69$ & 0.7217 \\
\hline MPVL & 0.19 & $(0.37)$ & $-0.36-0.63$ & 0.30 & $(0.22)$ & $-0.16-0.56$ & 0.5489 \\
\hline NDW & 8.5 & $(7.47)$ & $-6-21$ & 8.25 & $(10.18)$ & $-10-21$ & 0.0289 \\
\hline Lexical Rarity (\%) & 0.27 & $(1.12)$ & $-2.52-1.67$ & 0.49 & $(0.80)$ & $-1.84-1.02$ & 0.9239 \\
\hline \multicolumn{8}{|c|}{ Conversational Participation } \\
\hline M LT & 0.83 & $(0.24)$ & $0.53-1.39$ & 0.85 & $(0.47)$ & $0.44-0.92$ & 0.5203 \\
\hline \multicolumn{8}{|c|}{$\begin{array}{l}\text { N otes. } M L U=\text { M ean Length of Utterance, } M P V L=M \text { ean Pre-Verb Length, SYNCOM }=\text { Syntactic Complexity, } N D W=N \text { umber of Different } W \text { ords } \\
M L T=M \text { ean Length of Turn }\end{array}$} \\
\hline${ }^{\mathrm{N}} \mathrm{N}$ egative values oc & s scores & 5 exceed & mothe & & & & \\
\hline
\end{tabular}

Figure 1. Discrepancy scores between maternal and child language variables for CW S and CW DN S dyads.

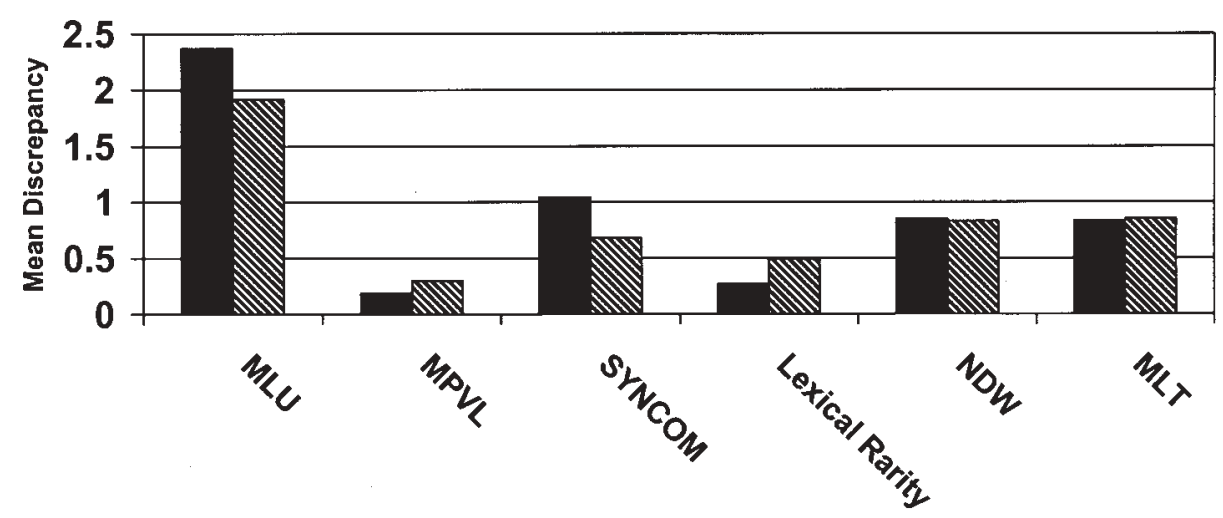

Language Measures

Dyads with CWS Dyads with CWDNS

\section{$\overline{\text { Discussion }}$}

The aim of this study was to examine parental linguistic input to children close to the onset of stuttering and to compsare the verbal behavior of parents of young children who stutter to that of parents of similar children who are typically fluent. Long-standing claims that some children who stutter experience a form of language demand imposed by advanced parental language models were evaluated via (a) between-group comparisons of mothers of stuttering and fluent children on measures of syntactic complexity, lexical diversity, and lexical rarity, and (b) estimation of relative demand of maternal language characteristics through between-group comparisons of within-dyad discrepancies between mothers and their children on these measures. No significant differences were found between mothers of children who stutter and mothers of fluent children on any of the measures, despite the use of a lenient statistical criterion for significance. This finding provides additional support for conclusions drawn by Nippold and Rudzinski (1995) in their recent review of the literature on parentchild interactions and stuttering: "There is little convincing evidence to support the view that parents of 
children who stutter differ from parents of children who do not stutter in the way that they talk to their children" (p. 978). The authors also concluded that "it cannot be stated with confidence that parents' speech behaviors contribute to children's stuttering or that modifying parents' speech behaviors facilitates children's fluency" (p. 986).

Discrepancies between scores of mothers and their children on these measures also failed to distinguish the groups under investigation. In other words, no differences were apparent in the extent to which parents from either group adjusted their language input to their children's current productive linguistic levels, either grammatically or lexically. This pattern suggests that mothers of children who stutter are equally as sensitive to their children's language abilities as mothers of children who are fluent.

This finding is not unexpected, however. There is strong support in the literature for the accuracy with which mothers appraise, and subsequently adjust to, their children's receptive and expressive language abilities (Broen, 1972; Cross, 1977; Rondal, 1985; Snow, 1977). Bernstein Ratner and Silverman (2000), using the same pool of participants examined in the present study, have recently provided converging support for parental adjustment to children's linguistic levels at the onset of stuttering. These authors noted several significant correlations between parents' scores on inventories regarding the language development of their children who stutter and their children's observed scores on various measures of receptive and expressive language abilities. As the present study provides evidence of these same parents modifying their verbal behavior (in addition to their beliefs) to reflect their children's productive levels, it seems that the premise underlying admonitions for parents "to 'move' from their often ...long, complex utterances to more normal...complexity" (Conture \& Melnick, p. 35) and reduce the complexity of their vocabulary when speaking to their stuttering child (Bloodstein, 1995) should be reconsidered. The present results, in conjunction with those of Bernstein Ratner and Silverman, show nothing abnormal or excessive in either the beliefs that parents of children who stutter have regarding their language performance or in the manner in which these parents interact with them linguistically.

In addition to the lack of evidence in support of advice that parents of children who stutter simplify their speech, the potential long-term ramifications of such advisements should be carefully examined. Although it is commonly suggested that parents who habitually use language that exceeds the syntactic and semantic levels of their children simplify their input, the languageacquisition literature strongly indicates that progress in language development is spurred when parents' speech is at a slightly higher level than their children's (Cross, 1977; Furrow, Nelson, \& Benedict, 1979; Murray, Johnson, \& Peters, 1990; Newport, Gleitman, \& Gleitman, 1977). Gleitman, Newport, and Gleitman (1984) found that, for toddlers between the ages of $1 ; 6$ and 2;7 (years;months), more complex maternal speech (i.e., higher MLU) actually facilitated language growth in these children. Similar relationships have also been demonstrated between rate of vocabulary acquisition in children and their exposure to maternal speech (Huttenlocher, Haight, Bryk, Seltzer, \& Lyons, 1991). If parental language input must occur at a level that will scaffold children's language growth, suggestions for parents to speak "on the level" of the child could have deleterious effects on children's acquisition of language. In fact, these studies imply, through association of more complex parental language and child language gains, that those children receiving less complex input make slower progress in language learning than some of their peers. Furthermore, these effects might be compounded for children, such as those in the present study, who are already demonstrating subclinical language weaknesses.

Although it was not possible to observe parental behaviors before, or immediately at, the onset of stuttering, we believe that the proximity of our observations to symptom onset provides an improvement over studies that observe parent-child interactions after the child has been stuttering for a long time and then attempt to posit a causal relationship between parent behaviors and the child's fluency. Most studies of parental-child interactions and stuttering have not controlled for children's age or time since onset of stuttering, two factors that "have the potential for advancing our understanding of the complex interaction between children who stutter and their environment" (Kelly, 1993, p. 211). Gaining further insight into the question of whether parental language behaviors precipitate stuttering onset, or change in reaction to their children's stuttering, is contingent upon the use of strict subject-selection criteria for age and time post stuttering onset. It should be noted, however, that, even with such controls, determining the relative contributions of parents of children who stutter and the children themselves (e.g., characteristics intrinsic to the child) to the problem remains a significant challenge (Nippold \& Rudzinski, 1995).

To illustrate this problem, let us consider the present study. The mothers of children who stutter in this study did not differ significantly from mothers of normally developing children on measures of language complexity. Nor were there significant between-group differences in the discrepancies between maternal-child scores on these measures. So, based on this design, it would appear that the children who stuttered were not being subjected to a different level of communicative demand 
than their fluent cohorts. However, we know that our children who stutter presented with subclinical weaknesses on standardized measures of receptive and expressive language ability (Bernstein Ratner \& Silverman, 2000), whereas the fluent children's language scores were generally more robust. That is, the children who stuttered uniformly performed less well than the fluent children-significantly so for two of the measures-but none of the children obtained scores that would identify them as exhibiting a language impairment. Furthermore, results from the present study show that children who stutter scored slightly lower than their fluent counterparts, though not significantly so, overall on several nonstandardized measures of linguistic ability. Given these factors, ascertaining what constitutes "demand" for these children becomes a complicated task; it is possible that the ability of children who stutter to assimilate parental linguistic input that parallels input to fluent children is reduced because of their linguistic vulnerability. Additional research will be needed to further clarify the nature of the demand that children who stutter might be experiencing.

\section{$\overline{\text { Future Research }}$}

As mentioned earlier, future investigations in this area should involve children matched for age and time elapsed since onset of stuttering symptoms. Furthermore, larger samples of children and their parents should be studied in order to generate more robust conclusions regarding the relationship between parental linguistic input and childhood stuttering.

Because of the design of this study, it is also difficult to weigh the possibility that parental language styles play a role in the persistence of stuttering, rather than its mere onset. We are aware of a recent longitudinal study by Kloth et al. (1999) that found a significant difference in the mean length of maternal utterance addressed during original intake sessions to children with persistent, as opposed to remitted, stuttering. However, these results are not easy to interpret. First, the persistent children were older at first presentation and produced longer utterances themselves; both features condition longer maternal length of utterance in parentchild interactions. Second, comparisons were performed between groups and did not address dyadic differences, as was done in this study. Third, MLU in words was the only linguistic measure analyzed. Although this study showed similar, nonsignificant trends in MLU, many other meaningful measures of children's and adults' language output showed no clear patterning between groups at all. We believe that research that uses multiple, converging measures of linguistic complexity will be more informative than those that select only one measure.
Fourth, earlier study of the same cohort (Kloth et al., 1995) had indicated shorter pre-symptom onset MLUs for mothers of children who stuttered than those who did not-a somewhat contradictory finding. Finally, the absolute difference in maternal utterance length that reached significance was a fraction of a word. Such findings reinforce the eventual difficulty of extending this entire line of research into the clinical setting; it is difficult to imagine counseling that encourages parents to reduce speaking turns by one word. Nonetheless, longitudinal studies examining relationships between speech and language characteristics of children who stutter, as well as parent-child dyadic differences on measures of these variables, will be very helpful in elucidating patterns of chronicity and remission in children who stutter.

For the children followed in this study, 3 of the 12 children were still stuttering at a one-year follow-up visit, whereas 9 of the children were no longer considered to stutter by either the evaluation team or the parents. These numbers are rather small and thus must be viewed with extreme caution. If we regroup our original discrepancy scores to create groups of fluent, recovered $(n=9)$ and chronic $(n=3)$ child-mother dyads (Figure 2), no clear patterns emerge to suggest that mothers of children who recover use language more closely or distantly attuned to their children than mothers of children who continue to stutter. (Lexical rarity was removed from the figure because of its relatively small distance scores overall.)

Because of the heterogeneity of the stuttering population, an important research direction will be in examining language abilities in children exhibiting varying levels of stuttering severity. Yaruss and Conture (1995) recently demonstrated a significant positive correlation between children's Total Overall Scores on the Stuttering Severity Instrument and speaking rate differences within parent-child dyads, indicating that some features of the speech of children who stutter might vary with stuttering severity. These results suggest that we might gain useful insight by establishing subgroups among children who stutter, in terms of stuttering severity, or, possibly, articulation and/or language characteristics. This is clearly an important notion to explore as we continue to investigate the relationship between speechlanguage characteristics and stuttering.

Finally, it is impossible to reject the notion that changes in parental language patterns might facilitate children's fluency or recovery from stuttering simply because intake data do not suggest readily observable differences between parents of fluent children, children who stutter, and/or children who recover or persist in stuttering. The true test of such a hypothesis would seem to be a carefully controlled intervention study, in which 
Figure 2. Intake discrepancy scores for CW DN S, children who were fluent (recovered) at one-year follow-up, and children who continued to stutter at follow-up (chronic).

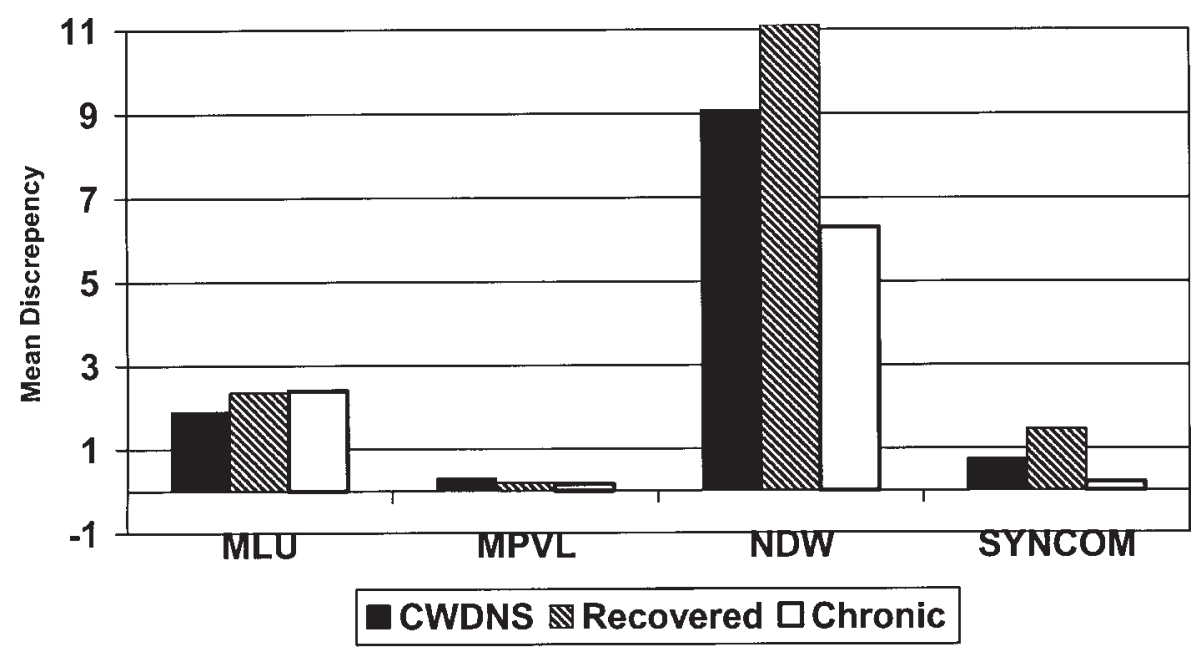

such changes were implemented in a structured and documented way and were "unbundled" from a variety of other recommendations that are conceivably either independently fluency-inducing or capable of interacting with parental communicative style (e.g., such as parental feedback to stuttering as employed in programs such as Lidcombe [Bonelli et al., 2000]). This type of research would be extremely valuable in evaluating the utility of parent-counseling components. The major focus of this article, however, has been to suggest that the language patterns of mothers of stuttering children do not appear to be unusual or unduly demanding per se. Such findings question the generalized advisement to reduce parental language "demand" in the treatment of early stuttering, and they suggest the need for empirical documentation of the efficacy of this therapy component.

\section{Acknowledgments}

The authors wish to thank Grace Yeni-Komshian, Froma Roth, and Stacy Silverman for their help with this research.

\section{References}

Beals, D. (1997). Sources of support for learning words in conversation: Evidence from mealtimes. Journal of Child Language, 24, 673-694.

Beals, D., \& Tabors, P. (1995). Arboretum, bureaucratic, and carbohydrates: Preschoolers' exposure to rare vocabulary at home. First Language, 15, 57-76.

Bernstein Ratner, N. (1988). Patterns of parental vocabulary selection in speech to young children. Journal of Child Language, 15, 481-492.
Bernstein Ratner, N. (1992). Measurable outcomes of instructions to modify normal parent-child verbal interactions: Implications for indirect stuttering therapy. Journal of Speech and Hearing Research, 35, 14-20.

Bernstein Ratner, N. (1993). Parents, children, and stuttering. Seminars in Speech and Language, 14, 238-248.

Bernstein Ratner, N., \& Silverman, S. (2000). Parental perceptions of children's communicative development at stuttering onset. Journal of Speech, Language, and Hearing Research, 43, 1252-1263.

Blake, J., Quartaro, G., \& Onerati, S. (1993). Evaluating quantitative measures of grammatical complexity in spontaneous speech samples. Journal of Child Language, 20, 139-152.

Bloodstein, O. (1995). A handbook on stuttering (5th ed.). San Diego: Singular Publishing Group.

Bloom, L., \& Lahey, M. (1978). Language development and language disorders. New York: John Wiley \& Sons.

Bonelli, P., Dixon, M., Bernstein Ratner, N., \& Onslow, M. (2000). Pre- and post-treatment characteristics of adult-child interactions of Lidcombe stuttering program participants. Clinical Linguistics and Phonetics, 14, 427-446.

Bornstein, M., Haynes, M., \& Painter, K. (1998). Sources of child vocabulary competence: A multivariate model. Journal of Child Language, 25, 367-394.

Botting, N., Conti-Ramsden, G., \& Crutchley, A. (1997). Concordance between teacher/therapist opinion and formal language assessment scores in children with language impairment. European Journal of Disorders of Communication, 32, 317-327.

Broen, P. A. (1972). The verbal environment of the languagelearning child (ASHA Monographs 17). Washington, DC: American Speech and Hearing Association.

Brown, R. (1973). A first language: The early stages. Cambridge, MA: Harvard University Press. 
Bruner, J. (1983). The acquisition of pragmatic commitments. In R. Golinkoff (Ed.), The transition from prelinguistic to linguistic communication (pp. 27-42). Hillsdale, NJ: Erlbaum.

Chall, J., \& Dale, E. (1995). Readability revisited: The new Dale-Chall readability formula. Cambridge, MA: Brookline Books.

Conture, E. G., \& Melnick, K. S. (1999). Parent-child group approach to stuttering in preschool children. In M. Onslow \& A. Packman (Eds.), The handbook of early stuttering intervention. San Diego: Singular.

Cross, T. (1977). Mothers' speech adjustments: The contribution of selected child listener variables. In C. Snow \& C. Ferguson (Eds.), Talking to children: Language input and acquisition (pp.151-188). London: Cambridge University Press.

Dunn, L., \& Dunn, L. (1981). Peabody Picture Vocabulary Test: Revised. Circle Pines, MN: American Guidance Service.

Fenson, L, Dale, P. S., Reznick, S., Thal, D., Bates, E., Hartung, J. P., Pethick, J., \& Reilly, J. S. (1993). The MacArthur Communicative Development Inventories. San Diego: Singular Publishing Group.

Fey, M. E., Leonard, L. B., \& Wilcox, K. A. (1981). Speech style modifications of language-impaired children. Journal of Speech and Hearing Disorders, 46, 91-96.

Furrow, D., Nelson, K., \& Benedict, H. (1979). Mothers' speech to children and syntactic development: Some simple relationships. Journal of Child Language, 6 , 423-442.

Gardner, M. (1990). Expressive One-Word Vocabulary TestRevised. Novato, CA: Academic Therapy Productions.

Gleitman, L. , Newport, E., \& Gleitman, H. (1984). The current status of the motherese hypothesis. Journal of Child Language, 11, 43-79.

Goldman, R., \& Fristoe, M. (1986). The Goldman-Fristoe Test of Articulation. Circle Pines, MN: American Guidance Service.

Guitar, B. (1998). Stuttering: An integrated approach to its nature and treatment (2nd ed.). Baltimore: Williams \& Wilkins.

Guitar, B., Schaefer, H. K., Donahue-Kilburg, G., \& Bond, L. (1992). Parent verbal interactions and speech rate: A case study in stuttering. Journal of Speech and Hearing Research, 35, 742-754.

Hadley, P., \& Rice, M. (1993). Parental judgments of preschoolers' speech and language development: A resource for assessment and IEP planning. Seminars in Speech and Language, 14, 278-288.

Hintze, J. (1999). NCSS 2000. Kaysville, UT: NCSS.

Huttenlocher, J. (1998). Language input and language growth. Preventive Medicine, 27, 195-199.

Huttonlocher, J., Haight, W., Bryk, A., Seltzer, M., \& Lyons, T. (1991). Early vocabulary growth: Relation to language input and gender. Developmental Psychology, 27, $236-248$.

Kasprisin-Burrelli, A., Egolf, D. B., \& Shames, G. H. (1972). A comparison of parental verbal behavior with stuttering and nonstuttering children. Journal of Communication Disorders, 5, 335-346.
Kelly, E. M. (1993). Speech rates and turn-taking behaviors of children who stutter and their parents. Seminars in Speech and Language, 14, 203-213.

Kelly, E. M. (1995). Parents as partners: Including mothers and fathers in the treatment of children who stutter. Journal of Communication Disorders, 28, 93-105.

Kelly, E. M., \& Conture, E. G. (1992). Speaking rates, response time latencies, and interrupting behaviors of young stutterers, nonstutterers, and their mothers. Journal of Speech and Hearing Research, 35, 1256-1267.

Klee, T. (1992). Developmental and diagnostic characteristics of quantitative measures of children's language production. Topics in Language Disorders, 12, 28-41.

Kloth, S., Kraaimaat, P., Janssen, P. \& Brutten, G. (1999). Persistence and remission on incipient stuttering among high-risk children. Journal of Fluency Disorders, $24,253-266$.

Kloth, S. A. M., Janssen, P., Kraaimaat, F. W., \& Brutten, G. J. (1995). Communicative behaviors of mothers of stuttering and nonstuttering high-risk children prior to the onset of stuttering. Journal of Fluency Disorders, 20, 365-377.

Langlois, A., Hanrahan, L. L., \& Inouye, L. L. (1986). A comparison of interaction between stuttering children, nonstuttering children, and their mothers. Journal of Fluency Disorders, 11, 263-273.

MacWhinney, B. (2000). The CHILDES project: Tools for analyzing talk (3rd ed.). Mahwah, NJ: Erlbaum.

Melnick, K. \& Conture, E. (2000). Relationship of length and grammatical complexity to the systemic and nonsystemic speech errors and stuttering of children who stutter. Journal of Fluency Disorders, 25, 21-45.

Meyers, S. C., \& Freeman, F. J. (1985a). Are mothers of stutterers different? An investigation of socialcommunicative interaction. Journal of Fluency Disorders, $10,193-209$

Meyers, S. C., \& Freeman, F. J. (1985b). Interruptions as a variable in stuttering and disfluency. Journal of Speech and Hearing Research, 28, 428-435.

Meyers, S. C., \& Freeman, F. J. (1985c). Mother and child speech rates as a variable in stuttering and disfluency. Journal of Speech and Hearing Research, 28, 436-444.

Miller, J. (1981). Assessing language production in children: Experimental procedures. Baltimore, MD: University Park Press.

Miller, J., \& Chapman, R. (1981). The relation between age and mean length of utterance in morphemes. Journal of Speech and Hearing Research, 24, 154-161.

Murray, A. D., Johnson, J., \& Peters, J. (1990). Finetuning of utterance length to preverbal infants: Effects on later language development. Journal of Child Language, $17,511-525$.

Newman, L. L., \& Smit, A. B. (1989). Some effects of variations in response time latency on speech rate, interruptions, and fluency in children's speech. Journal of Speech and Hearing Research, 32, 635-644.

Newport, E. L, Gleitman, H., \& Gleitman, L. R. (1977). Mother, I'd rather do it myself: Some effects and noneffects of maternal speech style. In C. Snow \& C. Ferguson (Eds.), 
Talking to children: Language input and acquisition (pp. 109-150). Cambridge, U.K.: Cambridge University Press.

Nippold, M. A. (1990). Concomitant speech and language disorders in stuttering children: A critique of the literature. Journal of Speech and Hearing Disorders, 55, 51-60.

Nippold, M. A., \& Rudzinski, M. (1995). Parents' speech and children's stuttering: A critique of the literature. Journal of Speech and Hearing Research, 38, 978-989.

Rondal, J. A. (1985). Adult-child interaction and the process of language acquisition. New York: Praeger.

Rustin, L., \& Cook, F. (1995). Parental involvement in the treatment of stuttering. Language, Speech, and Hearing Services in Schools, 26, 127-137.

Sachs, J., \& Devin, J. (1976). Young children's use of ageappropriate speech styles in social interaction and roleplaying. Journal of Child Language, 3, 81-98.

Schulze, H., \& Johannsen, H. S. (1991). Importance of parent-child interactions in the genesis of stuttering. Folia Phoniatrica, 43, 133-143.

Schwartz, H. D., \& Conture, E. G. (1988). Subgrouping young stutterers: Preliminary behavioral observations. Journal of Speech and Hearing Research, 35, 333-342.

Shapiro, D. (1999). Stuttering intervention. Austin, TX: Pro-Ed.

Snow, C. (1972). Mothers' speech to children learning language. Child Development, 43, 549-565.

Snow, C. (1977). Mothers' speech research: From input to interaction. In C. Snow \& C. Ferguson (Eds.), Talking to children: Language input and acquisition (pp. 31-50). London: Cambridge University Press.

Snow, C. (1986). Conversations with children. In P. Fletcher \& M. Garman (Eds.), Language acquisition: Studies in first language development (pp. 69-89). London: Cambridge University Press.

Sokolov, J. L., \& Snow, C. E. (Eds.). (1994). Handbook of research in language development using CHILDES.

Hillsdale, NJ: Lawrence Erlbaum Associates.

Starkweather, C. W., \& Gottwald, S. (1990). The demands and capacities model II: Clinical implications. Journal of Fluency Disorders, 15, 143-157.

Starkweather, C. W., Gottwald, S., \& Halfond, M. (1990). Stuttering prevention: A clinical method. Englewood Cliffs, NJ: Prentice-Hall.

Stephenson-Opsal, D., \& Bernstein Ratner, N. (1988). Maternal speech rate modification and childhood stuttering. Journal of Fluency Disorders, 13, 49-56.
Stuttering Foundation of America. (1993). Stuttering and your child (video). Memphis, TN: Author.

Templin, M. (1957). Certain language skills in children: Their development and interrelationships. Minneapolis: University of Minnesota Press.

Van Riper, C. (1973). The nature of stuttering. Englewood Cliffs, NJ: Prentice-Hall.

Wall, M., \& Myers, F. (1995). Clinical management of childhood stuttering (2nd ed.). Austin, TX: Pro-Ed.

Watkins, R. B., Kelly, D. J., Harbers, H. M., \& Hollis, W. (1995). Measuring children's lexical diversity: Differentiating typical and impaired language learners. Journal of Speech and Hearing Research, 38, 1349-1355.

Watkins, R.V., \& Yairi, E. (1997). Language production abilities of children whose stuttering persisted or recovered. Journal of Speech, Language, and Hearing Research, $40,385-399$

Weiss, A. L., \& Zebrowski, P. M. (1991). Patterns of assertiveness and responsiveness in parental interactions with stuttering and fluent children. Journal of Fluency Disorders, 16, 125-141.

Wiig, E., Secord, W., \& Semel, E. (1992). Clinical Evaluation of Language Fundamentals-Preschool. San Antonio, TX: Psychological Corporation.

Wilkenfeld, J., \& Curlee, R. (1997). The relative effects of questions and comments on children's stuttering. American Journal of Speech-Language Pathology, 6, 79-89.

Yairi, E. (1997). Home environment and parent-child interaction in childhood stuttering. In R. F. Curlee \& G. M. Siegel (Eds.), Nature and treatment of stuttering: New directions (pp. 24-48). Needham Heights, MA: Allyn \& Bacon.

Yaruss, J. S., \& Conture, E. G. (1995). Mother and child speaking rates and utterance lengths in adjacent fluent utterances: Preliminary observations. Journal of Fluency Disorders, 20, 257-278.

Received July 5, 2000

Accepted May 3, 2001

DOI: 10.1044/1092-4388(2001/088)

Contact author: Nan Bernstein Ratner, PhD, Department of Hearing and Speech Sciences, The University of Maryland, College Park, MD 20742. E-mail: nratner@hesp.umd.edu 


\section{Appendix. Procedures for Calculating Lexical Rarity, MPVL, and SYN COM.}

\section{Lexical Rarity}

Following procedures outlined by Beals and Tabors (1997), a list of all the words in all of the parent and child samples were compared with a list of 7,881 common words developed from the work of Chall and Dale (1995). The matching tokens were deleted, as were any proper names, exclamations, forms of address, slang, dialect, incorrect forms, and child culture words (e.g., "Teletubbies"). Children's imitative uses of rare words also were deleted. The resulting list therefore contains words unlikely to appear in the speech of most young children or in their immediate environment (parental speech, television, books).

\section{MPVL}

- Fillers, exclamations/ accessories (e.g., "There! I did it," "O kay, you put one on") and imperatives without overt subjects (e.g., "Go!") were excluded.

- N egative imperatives (e.g., "Don't go") were counted because of the expression of the auxiliary and negation before the main verb.

- Prepositions were included when they occurred before the main verb in secondary clauses, as in the utterance "I want to go."

\section{SYNCOM}

- The categories counted in SYN COM, and their components, are as follows: (1) Subject (noun, pronoun, noun phrase) (2) Verb (main verb, a uxiliary, particle, infinitive), (3) 0 bject (noun, pronoun, noun phrase), (4) Complement (prepositional phrase, predicate adjective, predicate noun, predicate pronoun, adverb).

- In accordance with the authors' rules, each category was counted as one unit (i.e., an auxiliary + main verb within one clause would receive a score of " 1 " for the Verb category), with the exception of the Complement category, in which each complement was counted separately.

- Each adjective in a series (e.g., "The big, blue ball...") was counted separately, as was each unit in a conjoined noun or prepositional phrase (e.g., "The boy and the dog...").

Conjunctions and fillers were excluded from the count. 